\title{
Understanding Pre-service Teachers' Emotion Experience During Teaching Practice in Tanzania: Causes, Management Strategies and the Impacts in Teaching
}

\author{
Jimmy Ezekiel Kihwele ${ }^{1,2}$ Mohamed Muhibu Chuma ${ }^{1}$ \\ 1.Faculty of Education, Beijing Normal University, No.19, Xinjiekouwai St, Haidian District, Beijing, 100875, \\ P. R. China \\ 2.Department of Education Foundations and Teaching Management, Mzumbe University, P. O. Box 5, Mzumbe, \\ Morogoro, Tanzania
}

The research is financed by authors

\section{Abstract}

Teacher's emotions serves as a central aspect of teachers' life as it govern classroom interactions and have a significant impact on students' learning. There are various factors that are associated with causing emotions and influencing teacher emotions like individual expectations, working environments or interaction patterns between sides. Given this, the study was structured to understand pre-service teachers' emotional experience during teaching practices. Specifically, the study sought to examine the causes, management strategies and its impact in the process of teaching and learning. Data were collected from 87 participants who were pre-service teachers who had been in teaching practice for eight weeks. The quantitative data collected were analysed by using MS excel 2007 and presented in descriptive statistics while qualitative data were analysed by using thematic analysis and supported with direct quotes. The findings show that pre-service teachers experienced emotions when their expectations about students' performances and active engagement were not met as well as when they achieved their goals of creating active learning environments. In situations that generated negative emotions, pre-service teachers sought advice from experienced teachers, they engaged in refreshing activities like listening to music, playing games or in classroom situations they were flexible to change to more interesting and engaging methods. The findings further revealed that impact of emotional experience is in two folds. On one side teachers become motivated to try new innovation and creativity when they experience positive emotion while on the other side they become discouraged when they experience negative emotions. Based on these findings, it is recommended that more studies on emotional dissonance should be conducted to help broader understanding of teacher emotions and how they can help improve their teaching.

Keywords: emotion experience, pre-service teachers, teacher education, teaching practice

DOI: $10.7176 / \mathrm{JEP} / 11-9-12$

Publication date: March $31^{\text {st }} 2020$

\section{Introduction}

Teacher emotions have been a central aspect of teachers' life of classroom interaction and have a significant impact on students' learning (Prosen, Vitulić and Škraban, 2011). Teacher-student relationship is central in classroom pedagogical interaction to facilitate learning process (Lasauskiene and Rauduvaite, 2015). The emotions teacher experiences like joy or anger affects the pedagogical interaction with students, how they prepare for teaching and their contribution to students' learning beyond the classroom which affects the learning environment. Prosen et al. (2011) adds that, apart from content and pedagogical knowledge, teachers need emotional knowledge to enhance smooth learning process. Teacher emotions are a result of factors ranging from personal expectations, daily practices at school to institutional issues like policies, workload and requirements in the working places. If teacher emotions are not well managed they can have a significant impact to the wellbeing of teachers and students, classroom pedagogical interaction and will have impact on students' academic performance and competence acquisition. Pre-service teachers are in a vulnerable situation due to their incompetence to manage emotions. Therefore, it is important to research pre-service teacher emotions, to understand the causes, how teachers manage their emotions and use them constructively for assisting the learning process (Prosen, Vitulić and Škraban, 2014).

\subsection{Defining teacher emotion}

Teacher emotion has been considered as an important aspect in the field of educational research. Studies have focused on teacher emotion due to awareness of the importance of understanding the role of emotion in education (Meyer and Turner, 2006; Lasauskiene and Rauduvaite, 2015; Lee et al., 2016). To define teacher emotion, different scholars have offered different explanations to suit their context and focus of studies. Emotions do not reside inside individuals or contexts independently; they emerge due to interaction that occurs during discharging professional duties and responsibilities (Chen, 2016). Researchers like Yan, Evans and Harvey (2011) associated with the relationship between teacher and wide aspects of classroom life like teacher student relationship, learning 
environment and engagement, students' emotions, teacher identity and ability to manage emerged uncertainty reforms in education.

Emotions are socially constructed as a person makes judgements regarding the perception of success or failure, simplicity or complexity in reaching the expectations or maintaining a set of standards or beliefs in a social context (Chen, 2016). Emotion is the process from perception and evaluation of stimulus, activation of bodily response, display of expressive gesture and a cultural label (Cross and Hong, 2012). There are varieties of stimuli that can trigger emotions among teachers. These might be their pre-determined expectations, change of policies and work requirements and failure to achieve self-planned goals. Teng, (2017) defined emotions as 'a complex state of feelings that result in physical and psychological changes, form an integral part of education'.

Burić and Frenzel (2019) explain teachers' emotions as anger or joy that resulted from both teacher and students that affects their relationship. Emotions can bring teacher and students more close in terms of pedagogical interaction or can distance them far apart. Chen (2016) defined emotion as a mystery phenomenon influenced by teacher behaviour and show positive expression such as joy, satisfying, pride and excitement and negative expression such as anger, frustration, sadness and anxiety. Cross and Hong (2012) also say emotional experiences involve personal environmental transactions internal and external features such as psychological and sociological, long term effect including emotional exhaustion and burn out that resulted from low job satisfaction and desire to leave professions.

\section{Literature review}

Emotions come from a wide range of experiences that pre-service teachers acquire through interacting with students. The emotion experiences are both positive like joy, love, and pride; and negative experiences like frustrations, hopelessness and anxiety (Burić and Frenzel, 2019). There are various factors that are associated with pre-service teacher emotional experience during their teaching practice. Inadequate support from colleagues at work places, inappropriate behaviour from parents like carelessness or irresponsible and reforms from educational policy that are too demanding for teachers to conform results to emotional experience (Burić and Frenzel, 2019). Negative emotional experience in pre-service teachers steadily developed due to factors related to working contexts and inadequate support from experienced teachers in host schools (Teng, 2017). Experiencing more negative emotions extinguish pre-service teachers' motivation and interest to become professional teachers. Also intrusion, administrative leadership approach, differences between teachers and administrators, the outcome of changes or reforms brought to the school by administrators or managers have been considered as factors for teachers' emotional experience (Chen, 2016). During classroom teaching and learning, teachers develop emotions due to students' responses, interactions and behaviour they show like making jokes, laughing loudly or smile (Kimura, 2010). These emotions may range from pleasant to unpleasant depending on the issue causing the emotion and may affect students' learning and teachers' commitment in teaching respectively.

Teacher emotions are expressed in different ways like changes in body temperature, rate of heartbeats and blood pressure (Sutton and Wheatley, 2003), tone of voice, facial expression and body posture (Prosen, Vitulić and Škraban, 2014). Teachers show their emotions like joy, enjoyment and wonder to students as they fulfil their responsibilities to show caring character and establish relationships that form the basis for teaching and learning which motivated student participation in classroom interaction (Kimura, 2010). Kimura further shows that negative emotions for teachers are inevitable like irritation, anger, sadness or embarrassment due to unpleasant behaviours of students or voluntarily repeating forbidden practices in the classroom. Chen (2016) also adds that, positive emotions can be satisfaction, pride, love, excitement and negative emotions can be frustration, fear and anxiety.

Teacher emotion experiences have a significant impact on teaching and learning in classroom situations. On students' side, teacher emotions at a time can influence interactions and involvement in learning activities or can limit. Teacher emotions play five important functions that include providing information, giving quality to experience, influencing cognitive processes, managing internal and external processes and providing motivation (Fried, Mansfield and Dobozy, 2015). Also Prosen, Vitulić and Škraban (2014) shows that pleasant emotion expression encourages learning process while unpleasant emotion expression limits learning and creativity to students since they will lead to emotional interaction between teachers and students. On the other hand, as a teacher, a significant impact of teacher emotions is that, can be revealed into aspects of education that influence teachers' cognitive process which inspired pedagogical thought and efficacy (Chen, 2016). Positive emotion encourages students to participate in the process and their desire to learn, hence improves the development relationship between teacher and students to achieve academic performance (Yan, Evans and Harvey, 2011). Thus pre-service teachers' emotions are to be well monitored from teacher training programs to teaching practices by both mentor teachers and teacher educators.

One of the management strategies of teacher emotions is to use regulation strategies which teachers considered to be helpful in reaching their teaching goals and become more effective in classroom management, as teachers regulating emotion is their responsibility and thus improve good relationship with students in class and become more professional (Lee et al., 2016). Fried, Mansfield and Dobozy (2015) argues that, when teachers 
employ emotion regulation in classroom setting, it could help them to improve positive emotions and reduce negative emotions. Tsang (2016) proposed two strategies that can be adopted by teachers to manage their emotions in the classroom setting, one strategy is surface acting and other is deep acting, thus surface acting can help teacher to reduce what could be expected in a particular situation in class regardless teacher's real emotions towards student, while deep acting help to change teacher feeling to match with appropriate emotional display in the classroom.

In Tanzania, teacher actions have revealed a certain level of emotional experience that has affected their teaching process. The Tanzania Teacher Commission (TSC) in 2019 said that more than 4000 teachers were terminated from their teaching jobs for the period from 2016 to 2019 due to disciplinary matters. These teachers administered heavy punishment to students; some did not attend classes, truancy and sexual affairs with students. Although not all offences are associated with teacher emotions, there are cases reported in the media showing the extent of teacher emotions through their actions. A teacher punished a student to death because the student helped another teacher to carry a handbag and later claimed the student stole the bag which was later found in the teachers' office (Kapaka, 2019). Also, the students in one secondary school who are asking the government to address the tendency of teachers to give harsh punishment by enacting by-laws that will guide the process of administering punishment that will not affect students learning (Lubasi, 2019). The same has been claimed by Kasika (2018) and requested teachers to control their emotions when implementing their duties, failure to control emotions they will find themselves forcing students to do things which are inhumane. These actions reveals teacher burnout due to emotion experienced for a long period in their teaching careers. To avoid such situations, it is necessary to conduct study to understand pre-service teachers' emotional experience during their teaching practices as a crucial part in integrating pre-service teachers into practical and real school and classroom setting.

Little has been studied about pre-service teachers' emotions and its impacts on their future teaching prospects. Studies have focused on pedagogical competencies like preparedness to implement competence-based curriculum (Tarmo, 2016) and studies related to beliefs about the pedagogical reforms involving learner cantered teaching approaches (Paulo, 2014). Researchers like Lyakurwa and Tungaraza (2013) studied about pre-service teachers' attitude towards inclusive education. Again, Raphael and Mtebe (2017) studied about pre-service teachers' selfefficacy beliefs towards educational technologies integration in schools. Therefore, studying about pre-service teachers' emotional experience will add knowledge to the broad spectrum of insights concerning pre-service teachers. This study will answer three research questions; - what factors are associated with the development of teacher emotions in secondary schools? What are the impacts of teacher emotions on classroom teaching and learning? What strategies or mechanisms do teachers employ to manage their emotions in that context?

\section{Methodology}

The study employed a mixed method case study design that was conducted at Mzumbe University in Tanzania. Teaching practice is considered as a course, where students attend teaching practice after the end of the second semester of the first year. Pre-service teachers are required to spend 8 weeks in schools where they will be implementing classroom teaching activities and other administrative duties like to be teachers on duty for the specified period, to assist class coordinators and student discipline office. The population of the study were the Bachelor of Education degree students who in this context are referred to as pre-service teachers. The study involved second year pre-service teachers at the university as key informants. The respondents had already completed their first teaching practice duration. These respondents were chosen since this was their first practice as teachers, and what they experienced at first time was important in order to understand the emotions they experienced. These respondents had the required experiences from teaching practice and activities they performed hence could help in providing real emotional experiences they faced during their period in teaching practice. Data were collected through open ended questionnaires since they had an opportunity for respondents to raise inner issues to explain more about their choices that could help a researcher to go beyond the limit of the items (Cohen, Manion and Morrison, 2007). A total of 87 (100\%) respondents filled in the questionnaires. The questionnaire items involved gender if they have experienced emotions during their teaching practice, which positive emotions they experience (between happiness, satisfaction, wonder, pride, love and excitement), what were the reasons behind these positive emotions, which negative emotions they experience (between sadness, frustration, anger, fear, confusion and embarrassment), what were the reasons behind these negative emotions experienced and how did the emotional experience affect the teaching practices. Respondents were asked to select all choices that reflect their emotional experiences. Quantitative data were analysed in percentages and presented in descriptive statistics while the qualitative data were analysed based on the content and categorized into emerging themes. The presentation of the findings and discussion helps to make sense of the data collected and answer the research questions.

\section{Findings and discussion}

The findings from the study show that most pre-service teachers have experienced emotions during their teaching 
practices. No significant differences on emotional experience between the genders were observed except in few items. The factors associated with emotions ranges from individual pre-service teachers' expectations before teaching practices, the professional and environmental reality they faced during the teaching practices and emotions associated with assessment from the university.

\subsection{Factors for emotional experiences to pre-service teachers}

Pre-service teachers have experienced both positive and negative emotions during their teaching practice period. The findings resonate with Nguyen (2014) showing that pre-service teachers experience both positive and negative emotions during their period in teaching practice. All 87 respondents $(100 \%)$ agreed that at some point they were emotional due to various reasons. Some pleasant issues resulted in positive emotions and unpleasant factors led to negative emotions

4.1.1 Factors for positive emotions

Pre-service teachers experienced more positive emotions in happiness and satisfaction and less in pride and excitement. Males experienced more love than females while females experienced more wonder than males. The social constructs about gender might explain the reasons behind the variation in emotional experiences by gender.

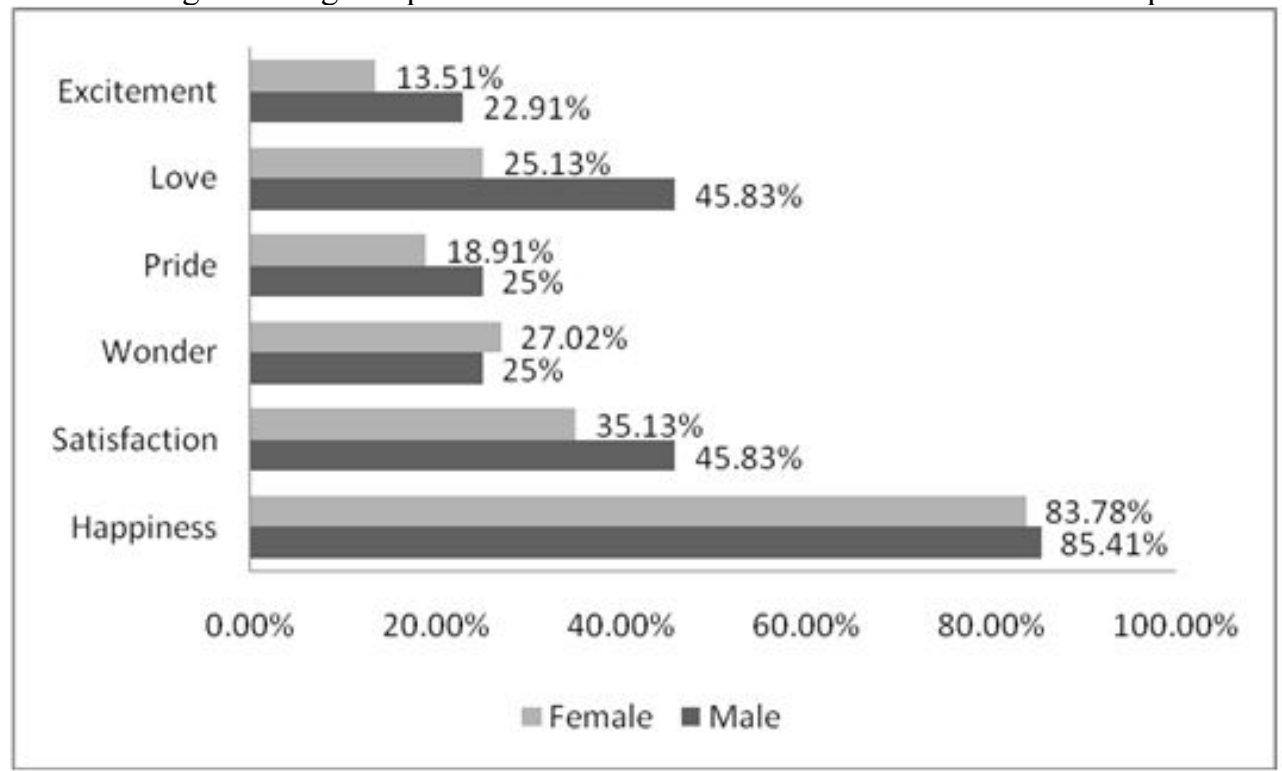

Figure 1: Positive emotions experience of pre-service teachers by gender

Pre-service teachers experienced positive emotions when their expectations on teaching goals were achieved in the places where they were teaching. The cooperation of students in classroom situations, motivated to participate in the classroom activities and good performance in assignments excited teachers. Pre-service teachers felt satisfied when they were given to teach the topics that they competently master them and managed to deliver them well in the classroom. One respondent said; - "I felt very happy to teach the topic that I was competent with and my students understood. Later when I gave them an assignment they performed well". This further enhanced their happiness since it attracted more students to attend the class and ask more questions and on some occasions it sparked debates and discussions. Positive emotions experiences energised pre-service teachers to extend their support for more positive results.

The existence of supportive work environment like cooperation with experienced teachers in the host school in providing guidance and motivation, the support and encouragement from the head of school gave them more energy to work hard and feel valued and loved. Effective modelling and mentorship by in-service teachers is said to be among the factors that motivate pre-service teachers and enhance their positive emotions. The climate motivated pre-service teachers to bring new ideas and use their extra time to assist learners to improve students' learning. Educational leaders play an important role in promoting innovation and creativity through their leadership styles.

Another factor that led to pre-service teachers experiencing positive emotions was the intrinsic motivation towards teaching profession. Response from one pre-service teacher shows that satisfaction was due to self esteem and pride of becoming a teacher. In the response the respondent said; - "I felt proud as a teacher, doing the work that I have been admiring for a long time, to assist students in their learning process. I was happy". Pre-service teachers feel satisfied when they are autonomously practicing the career of their dream. The power to manage students and lessons in the classroom and through pedagogical interactions, they achieve self-fulfilment hence experience positive emotions. 


\subsubsection{Factors for negative emotions}

Pre-service teachers experienced more negative emotions in sadness, anger, fear and confusion while they experienced less negative emotions in frustration and embarrassment. Males experienced more sadness, frustration, fear and confusion than their counterparts while females experienced more anger and embarrassment than males.

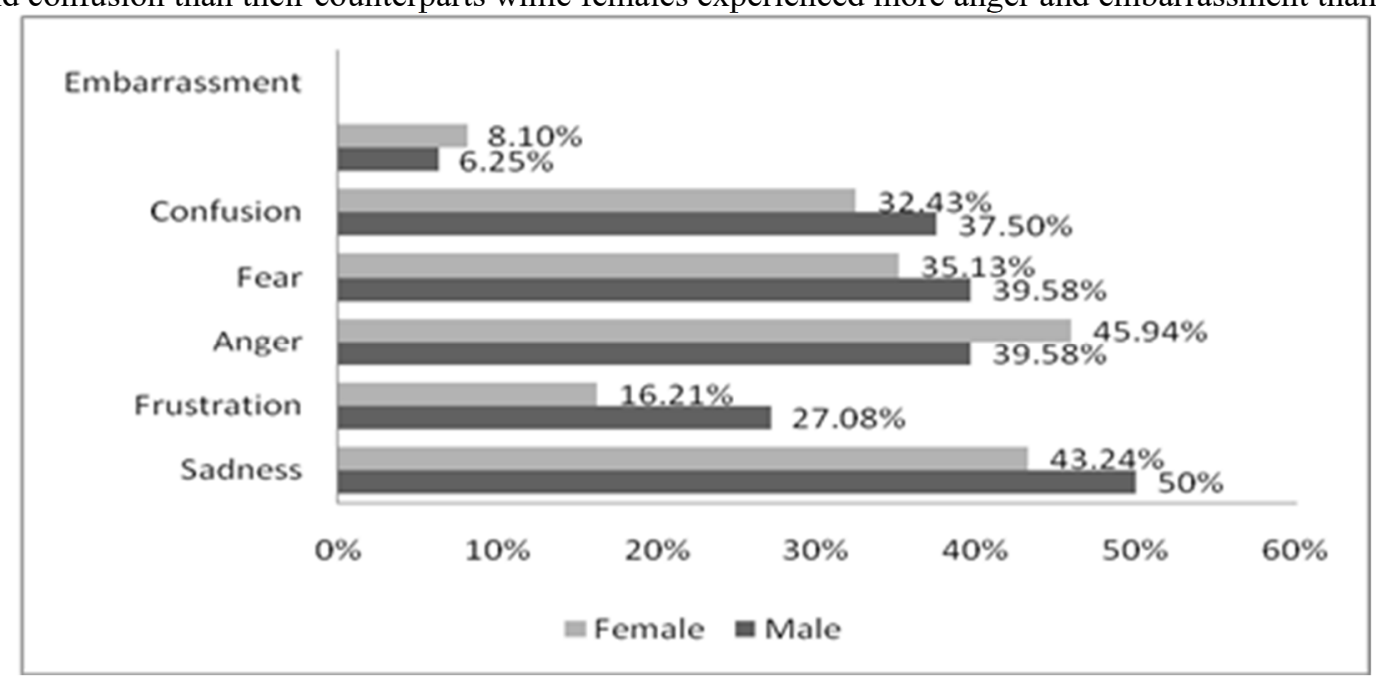

Figure 2: Negative emotions experience of pre-service teachers by gender

Negative emotions were experienced by pre-service teachers when they did not fulfil their expectations related to how they perceived teaching activities should be. Sadness was felt when students performed poorly in assignments contrary to what they expressed during the lesson. Again when the teacher believed to have an active class with students participating in discussions and then they met with students who were sleeping in the class and inactive students who did not participate in class activities, this experience made them angry and sad. Also when students misbehave in the class like not respecting the teacher or did not follow directives, teachers felt embarrassed. One respondent felt confused and said; - "I was sad because students did not show respect, they did not write assignments I gave, they kept talking in the class". Pre-service teachers should be aware that they are the one to train students to have the required level of respect. Through these behavioural misconducts, teachers should understand students and transform them to better students who respect teachers.

Teaching for the first time contributed to feeling that resulted in experiencing negative emotion. Pre-service teachers felt frustrated and confused because they feel like they had not mastered the content of subjects they teach and the way students perceived them as student teachers was a challenge to them. The feeling of incompetent eroded their self confidence and developed fear every time they were about to enter in the class to teach. This is supported by the quote from one pre-service teacher "It was my first time to teach as a teacher, I felt I am less competent, I had low self efficacy and I think that affected my confidence". Experienced teachers should work closely with pre-service teachers to mentor them and encourage them. This pre-service teacher experienced "reality shock" of the actual classroom teaching situation contrary to their prior self efficacy since their enrolment to the period before teaching practice. The bond is important in developing confidence and broadens experiences of the less competent pre-service teachers.

During the teaching practice period, pre-service teachers had been waiting for assessment from university lecturers but in the school environment they had inadequate resources forcing them to design materials and teaching aids. This added to the tension of fear and frustrations since they had to incur cost to obtain the materials. Numbers of students in the classes were higher than their expectations meaning they will have more responsibilities to accomplish like marking assignments and tests and assisting those who perform low. English language is used as language of instruction, pre-service teachers had low level of proficiency hence became an obstacle in classroom communication that contributed to fear. These caused pre-service teachers to lose confidence thus attracting negative emotions.

Apart from classroom teaching activities, administrative tasks were challenging to them since the experienced teachers in host schools thought pre-service teachers knew managerial duties while they are not aware of. They were assigned activities like being teachers on duty to handle and manage weekly activities and write reports, but most of them did not know what to do or even how the weekly reports are prepared. Lack of this key information from experienced teachers in the hosting institutions lead to student teachers to be in dilemma most of the time that led to fear, anger and confusion. 
disturbs teacher-student relationships. The faulty relationship discourages both teachers and students as it affects their self confidence which is crucial in the effective learning process. The emotion experiences interfere with the natural flow of the learning process, increasing teacher-student social distances. As A result, students will hate the teachers and teachers will develop negative perceptions of the students. One pre-service teacher responded by saying; - "emotions [negative] makes students hate teachers, to hate the subjects, leading to poor performance at the end". In other cases, pre-service teachers failed to accomplish the planned lesson on time because they had to repeat previous sessions or give more time to students to complete the assignments they did not finish. Teachers should learn from both negative and positive emotions and they provide important feedback that can be used as a resource to understand the situations, circumstances or to understand their students and act accordingly to improve the learning process.

Positive emotions motivate teachers and students through creating a favourable environment for meaningful learning where there will be active participation in classroom learning activities. The favourable atmosphere for learning includes mutual respect, love and adequate resources that enhance interaction for learning. Apart from promoting students' confidence, it develops an inquiry mind where students and teachers can interact even out of the classroom. In three cases, pre-service teachers who experienced positive emotions devoted their extra time to assist students learning. To reduce these impacts and promote effective learning processes, pre-service teachers should be trained in advance to prepare themselves before starting their teaching practices. Experienced teachers in host schools should work hand in hand to provide assistance throughout the practicum period, mentoring them to understand the events and environments.

Experiencing both negative and positive emotions enhance teachers' resilience abilities in understanding and learning how to manage situations and circumstances in teaching and learning activities. Learning to teach for these pre-service teachers is also learning to deal with emotions and solving problems they encounter in their course of teaching practice which develops their future being. Inexperienced pre-service teachers have higher expectations of how teaching is, but they face different experiences resulting in emotional feelings. The more they experience these emotions whether negative or positive the more they learn and become aware of the situations and circumstances happening in the teaching process when they interact with students. Pre-service teachers should be mentored to expect unexpected in the teaching career. Their expectations are not in harmony with changing moods of students and changing nature of the working environments.

\subsection{Strategies to manage emotions in teaching practices}

Pre-service teachers had different reactions and strategies to confront these emotional experiences that could not distract them from effective teaching activities to facilitate learning. Regarding negative emotions, which preservice teachers were more concerned about as to maintain their normal teaching practices, students developed strategies to make them resilient to the emotions they were experiencing.

Taking time off from that specific activity and trying to do things that will keep their mood positive like listening to music, playing games, interacting with friends and other members in that neighbourhood helped then to stand issues that caused negative emotions. One respondent said; - "I overcame the emotional feelings through socializing with experienced teachers and other community members around that area". Consulting experienced teachers on how to handle the situations they were in helped them to gain confidence and better ways of managing their emotions. Teachers then had more time to talk to the students who were misbehaving or did not participate in teaching and learning activities.

In the classroom situations, pre-service teachers tried different participatory teaching methods that engaged students individually or in the groups. This included teachers to be flexible to designing, improvising and using more teaching aids that will spark discussion to students and bring new ideas. This is confirmed by the response from one respondent; - "I managed the negative emotion by applying different teaching methods like group discussion, group presentations and asking oral questions. This helped to change the mood of the class and the lesson was well delivered".

Pre-service teachers took more time to learn and understand their learners, their behaviours, interests and needs. In some cases, experienced teachers provided mentorship to broaden avenues of acquiring teaching competencies. From this observation, pre-service teachers collaborated with students to develop a code of conduct that will guide how students should behave in the classroom during teaching and learning. The code of conduct included punishments and rewards to promote desired behaviours that will influence the learning process. Furthermore, in other cases pre-service teachers provided more assignments to keep students busy in learning. Lastly, another strategy used to manage the negative emotions was for pre-service teachers to ignore things that could develop and lead to emotional experiences.

\section{Conclusion}

Emotions experiences are an inevitable aspect for pre-service teachers in facilitating the learning process. There are many factors that will lead to emotional experience, some are under teachers' ability to manage and solve and 
some factors cannot be easily solved by pre-service teachers. Pre-service teachers should understand that factors that lead to emotional experience are the one helping them to transition from novice to experienced teachers. Managing the emotions during teaching and learning process can be termed as an important step towards professional maturity. Although professional maturity is not all about understanding positive and negative emotions and being able to manage them that they may not affect the teaching process, it requires general understanding of teacher emotions. Emotional experience is a small aspect in teacher emotions. Further studies should focus on emotional dissonance to understand how teachers' balances these emotions from what they experience and to what the schools want to be achieved. Effective teaching expects teachers to be affectionate to students in the existence of positive emotions. Teacher education institutions should train pre-service teachers more about emotional experiences and host schools should assist pre-service teachers to experience the real side of teaching to build them to more quality and passionate teachers. Teacher educators in teacher training universities and colleges must also have strong base and consideration on knowing, nurturing and developing the pre-service teachers' emotions emerging from their efficacy, beliefs and perceptions about the job and their professional development, which are to be strongly enhanced through teaching practice.

\section{References}

Burić, I. and Frenzel, A. C. (2019) 'Teacher anger: New empirical insights using a multi-method approach', Teaching and Teacher Education, 86. doi: 10.1016/j.tate.2019.102895.

Chen, J. (2016) 'Understanding teacher emotions: The development of a teacher emotion inventory', Teaching and Teacher Education, 55, pp. 68-77. doi: 10.1016/j.tate.2016.01.001.

Cohen, L., Manion, L. and Morrison, K. (2007) Research methods in education. 6th edn, Professional Development in Education. 6th edn. New York: Routledge.

Cross, D. I. and Hong, J. Y. (2012) 'An ecological examination of teachers' emotions in the school context', Teaching and Teacher Education. Elsevier Ltd, 28(7), pp. 957-967. doi: 10.1016/j.tate.2012.05.001.

Fried, L., Mansfield, C. and Dobozy, E. (2015) 'Teacher emotion research: Introducing a conceptual model to guide future research', Issues in Educational Research, 25(4), pp. 415-441.

Kapaka, R. (2019) 'Mwalimu aliyemchapa mwanafunzi ahukumiwa kunyongwa hadi kufa', Mwananchi, 7 March. Available at: http://mtanzania.co.tz/mwalimu-aliyemchapa-mwanafunzi-ahukumiwa-kunyongwa-hadi-kufa/.

Kasika, S. (2018) 'Adhabu hizi za kokoto, wanafunzi wana kazi', IPP Media, 19 July. Available at: https://www.ippmedia.com/sw/safu/adhabu-hizi-za-kokoto-wanafunzi-wana-kaz.

Kimura, Y. (2010) 'Expressing Emotions in Teaching: Inducement, Suppression, and Disclosure as Caring ProfessionExpressing Emotions in Teaching : Inducement, Suppression, and Disclosure as Caring Profession', Educational Studies in Japan, 5(0), pp. 63-78. doi: 10.7571/esjkyoiku.5.63.

Lasauskiene, J. and Rauduvaite, A. (2015) 'Expression of Pre-service Teachers' Emotional Competency in their Educational Practice', Procedia - Social and Behavioral Sciences. Elsevier B.V., 205(May), pp. 103-109. doi: 10.1016/j.sbspro.2015.09.031.

Lee, M. et al. (2016) 'Teachers' emotions and emotion management: integrating emotion regulation theory with emotional labor research', Social Psychology of Education. Springer Netherlands, 19(4), pp. 843-863.

Lubasi, S. (2019) 'WANAFUNZI WAOMBA SHERIA NDOGO KUWAONDOLEA "UTATA”, HabariLeo, 13 December. Available at: https:/habarileo.co.tz/habari/2019-12-135df32f38c795f.aspx (https://www.facebook.com/dailynewstz).

Lyakurwa, S. E. and Tungaraza, F. D. (2013) 'Pre-service teachers' attitudes towards inclusive education in Tanzania', Journal of Culture, Society and Development, 2(1997), pp. 11-17.

Meyer, D. K. and Turner, J. C. (2006) 'Re-conceptualizing emotion and motivation to learn in classroom contexts', Educational Psychology Review, 18(4), pp. 377-390. doi: 10.1007/s10648-006-9032-1.

Nguyen, M. H. (2014) 'Preservice EAL teaching as emotional experiences: Practicum experience in an Australian secondary school', Australian Journal of Teacher Education, 39(8), pp. 62-84. doi: 10.14221/ajte.2014v39n8.5.

Paulo, A. (2014) 'Pre-Service Teacher's Preparedness to Implement Competence-Based Curriculum in Secondary Schools in Tanzania', International Journal of Education and Research, 2(7).

Prosen, S., Vitulić, H. S. and Škraban, O. P. (2011) 'Teachers' emotional expression in interaction with students of different ages', Center for Educational Policy Studies Journal, 1(3), pp. 141-157.

Prosen, S., Vitulić, H. S. and Škraban, O. P. (2014) 'Teachers' Emotional Expression in the Classroom Öğretmenlerin Sinıfta Duygusal İfadesi', H. U. Journal of Education, 29(1), pp. 226-237.

Raphael, C. and Mtebe, J. (2017) 'Pre-Service Teachers' Self-Efficacy Beliefs towards Educational Technologies Integration in Tanzania.', Journal of Learning for Development, 4(2), pp. 196-210.

Sutton, R. E. and Wheatley, K. F. (2003) 'Teachers' Emotions and Teaching: A Review of the Literature and Directions for Future Research', Education Psychology Review, 15(4), pp. 327-358.

Tarmo, A. (2016) 'Pre-service science teachers' epistemological beliefs and teaching reforms in Tanzania', Cogent 
Education. Cogent, 3(1).

Teng, M. F. (2017) 'Emotional development and construction of teacher identity: Narrative interactions about the pre-service teachers' practicum experiences', Australian Journal of Teacher Education, 42(11), pp. 117-134. doi: 10.14221/ajte.2017v42n11.8.

Tsang, K. K. (2016) 'Sociological Research on Teachers' Emotions: Four Approaches and the Shared Themes', Journal of Sociological Research, 6(2), p. 150. doi: 10.5296/jsr.v6i2.8749.

Yan, E. M., Evans, I. M. and Harvey, S. T. (2011) 'Observing emotional interactions between teachers and students in elementary school classrooms', Journal of Research in Childhood Education, 25(1), pp. 82-97. doi: 10.1080/02568543.2011.533115. 